\title{
Reliability of Modified Owl Technique in Reduction of Huge Breasts of Different Sizes
}

\author{
RIHAM LASHIN, M.D. and AHMED ELSHAHAT, M.D. \\ The Department of Plastic Surgery, Faculty of Medicine, Ain Shams University, Cairo, Egypt
}

\begin{abstract}
Background: Breast enlargement can range from mild to moderate to severe enlargement, which is called the gigantomastia. Different pedicles can be used for transfer of nipple areola complex to its new position. Owl technique involves transposition of the nipple areola complex on superior dermoglandular pedicle which is not suitable for gigantomastia. Modification in form of transposition of the nipple areola complex on superior dermal pedicle allowed the use of this technique in management of gigantomastia.
\end{abstract}

Patients and Methods: Fifty patients were operated upon using this technique in the period between June 2015 and June 2016. Seating Owl-shaped markings of Oscar Ramirez were used. Follow-up for at least six months showed maintenance of the results.

Results: Partial affection of areola vascularity occurred in one patient with previous application of port-a-cath on the same side chest wall.

Conclusion: This modification gives reliable successful results in reduction of different size huge breasts.

Key Words: Owl technique - Huge breasts.

\section{INTRODUCTION}

The breast is a modified sweat gland (one of the skin appendages), it is located within the superficial fascia of the anterior thoracic wall [1-3]. The dominant supply to the integument of the anterior chest is from the following sources: The internal thoracic artery medially, especially from the $2^{\text {nd }}$ and $3^{\text {rd }}$ interspaces; the lateral thoracic artery laterally; the anterior intercostal arteries inferiorly, especially from the $4^{\text {th }}$ and $5^{\text {th }}$ intercostal spaces and from the acromiothoracic perforator superiorly. These vessels anastomose in the vicinity of the nipple-areola complex (cutaneo-glandular plexus) [3-5]. Corduff and Taylor imagine the developing breast as a tissue expander which is fixed to the skin at the nipple. Expansion results in elongation of the supplying vessels and their compression towards the periphery of the gland forming a vascular hood [6]. Ricbourg termed this vascular hood "cutaneo-glandular plexus" [7]. The breast is supplied by vessels that penetrate the gland from the vascular hood following the connective tissue framework between the breast lobules [6]. Therefore the glandular tissue is supplied by retrograde flow from the cutaneo-glandular plexus.

Breast enlargement can range from mild to moderate to severe enlargement, which is called the gigantomastia. The goals of reduction mammoplasty are to reduce the volume of a breast, to create an aesthetic shape that is stable over time, to maintain blood supply and innervation to the areolar complex, and to make fine limited scars [8].

Different techniques have been used for breast reduction, these techniques used different types of incisions including techniques with minimal scars. Reduction mammoplasty has traditionally been done using the Wise pattern of incision. Because of the box-like effect in breast shape, the lack of projection, and the long scars associated with the inverted $\mathrm{T}$ incision, two techniques have emerged as alternatives: The vertical reduction of Lassus/ Lejour [9-13] and the "round block" periareolar technique popularized by Benelli [14]. Each of these techniques has its pros and cons.

The Owl technique for breast reduction was described as an alternative to the pure vertical and periareolar incisions. Ramirez choose the name owl for his technique because the shape of the initial skin markings resemble a seating owl [15]. The "owl" incision combines the features of the large periareolar reduction (Benelli's) and the vertical reduction (Lassus/Lejour); the horizontal inframammary scar is either made very short or completely eliminated. The short horizontal excision eliminates any resultant "dog ears" in the new inframammary fold [15]. Different pedicles can be 
used for transfer of nipple areola complex to its new position. Owl technique involves transposition of the nipple areola complex on superior dermoglandular pedicle. Volume reduction is done through a heart-shaped parenchymal resection, leaving the nipple-areolar complex over a superiocentral pedicle. Maintenance of the central parenchyma behind the nipple-areolar complex and mobilization of the vertical pillars toward the center of the breast give excellent projection and diminish the lateral fullness. There is no skin or parenchymal undermining in Ramirez technique [15]. Excellent results are obtained immediately on the operating table, and large volumes of glandular resection and correction of severe ptosis can be accomplished without compromising vascularity of either the nipple-areolar complex or the skin flaps using this technique [15]. Ramirez in his study mentioned that Owl technique can be used for reduction of any huge breast with any size of enlargement [15], although limitation to this technique is that in huge sizes of the breast "gigantomastia" using the Owl technique is not feasible due to bulkiness of the superior dermoglandular pedicle which will be problematic in transposing and in-setting the long bulky superior dermoglandular pedicle, so it is more suitable in reducing the moderate sizes of breast hypertrophy and in cases of mastopexy.

Previous modification of the Owl technique by Safe et al., 2007 was to extend the parenchymal resection underneath the pillars (leaving the superficial half of each pillar) to allow larger resection in cases of gigantomastia, but without undermining or thinning of the pedicle [16]. In our current modification to the Owl technique, we do undermining and thinning of the superior pedicle through continued parenchymal resection upward underneath the nipple areolar complex and the upper pole of the breast, making it dermal rather than dermoglandular pedicle, undermining and thinning the superior pedicle creates a roomy space underneath the area of the nipple areola complex and the upper pole of the breast, that allow easier transposition and in-setting of the of the nipple areolar complex to its new position, and on the other hand, thinning of the pedicle allows a larger parenchymal resections aiming at using this technique in reduction of huge breasts of different sizes "gigantomastia".

\section{Aim of work:}

Owl modification in the form of undermining and thinning the superior pedicle and transposition of the nipple areola complex on superior dermal pedicle, allowed the use of this technique in management of gigantomastia.

\section{PATIENTS AND METHODS}

Fifty patients were operated upon using this technique by the senior author. They complained of different degrees of huge breast hypertrophy. This study was performed between June 2015 and June 2016. Preoperative examination and investigations revealed no suspicion of any malignancy in the breast. All patients were fit for surgery. Diabetic patients were excluded from the study. Smoking stopped for two weeks preoperatively in patients who smoke. Preoperative photographs of each patient (frontal, oblique, and dead lateral views) were taken. Figs. $(2,3,4)$ show on the left side the preoperative photos of the breasts of three of our patients.

\section{Skin markings:}

We used the seating Owl shaped markings that have been mentioned by Ramirez [15]. Markings were performed with the patient in an upright standing position as follow: 1- Determination of the meridian for each breast. 2-Determine the projection of each meridian on the abdomen. 3Determination of the uppermost point of elevated areola. The projection of the inframammary fold onto the anterior surface of the breast was marked. This will indicate the position of the upper border of the new areola and not the nipple itself $[17,18]$. 4- By a French malleable measure a curve or a semicircle $24 \mathrm{~cm}$ in length over the uppermost point of the elevated areola was drawn. The curve of this semicircle will vary (manipulated) according to the size of the breast and the distance the nipple and areola will have to move on the superior pedicle. The larger the breast, the wider this new areola design will be, and the longer the superior pedicle, the wider this semicircle will be $[\mathbf{1 7}, \mathbf{1 8}]$. The length of the periareolar component was about 1.5 times the circumference of the new areola (the circumference of $5 \mathrm{cms}$ diameter areola is $16 \mathrm{cms}$ ). 5- Shift the breast right and left to connect the medial and lateral most points of the areolar semicircle to the line drawn on the abdomen [This lower part formed the vertical component (the body) of the Owl]. With the patient facing forward the breast is pushed laterally with one hand and a line projecting the vertical axis on the abdomen is then drawn on the medial part of the breast representing the medial line. The breast is then displaced medially, and in a similar fashion the lateral line is drawn. These medial and lateral markings not only determine the amount of skin and breast excision, they also determine the size of the skin envelope and the size of the reduced breast. The amount of force applied to the breast while making these marks is therefore most important. The stronger the force, 
the greater the distance between the two lines and hence the greater the volume of the reduction. These markings are then extended upward to meet the areola markings, and will join the medial and lateral markings, and the end point is $2-3 \mathrm{~cm}$ above the preexisting infra-mammary line $[\mathbf{1 7}, \mathbf{1 8}]$. 6Horizontal line (the feet of the Owl) is then drawn representing the transverse component of the inverted $\mathrm{T}$ design, it eliminate any resultant "dog ears" in the new inframammary fold.

\section{Surgical technique:}

All patients underwent the surgery under general anesthesia. The patient is operated upon in a supine position with the arms extended at $70^{\circ}-90^{\circ}$ on an arm board. The patient lie symmetrically on the operating table with shoulders and arms on each side at the same level. The peri-areolar component was de-epithelized around the new areola. Deepithelization extended at least $2 \mathrm{~cm}$ below the limits of the new areolar border.

Excision of breast parenchyma as planned for reduction was done from the vertical component, leaving two (medial and lateral) parenchymal pillars. Then inferiorly in the area between the old and new inframammary folds.

The dissection continues straight through the breast tissue down to the pectoralis fascia. It is preferable to do this with the cutting and coagulating electrocautery in order to minimize blood loss. The dissection is continued from below upward under the pre-existing nipple-areola and up toward the new nipple-areola position. The bulk of the breast tissue to be resected has now been mobilized. The central and lower breast tissue is now mobilized and semi-detached from the de-epithelialized superior pedicle, usually $2-3 \mathrm{~cm}$ below the areola margin, but still attached superiorly.

We extend the parenchymal resection upward underneath the nipple-areola complex (NAC) and underneath the superior pedicle, with the superior pedicle is thinned out distally up to $2-3 \mathrm{~cm}$ in thickness (Fig. 1a), and the dissection continues upward beyond the level of the projected nippleareola at the upper pole of the breast, and then down to the chest wall using cutting electrocautery. This makes the pedicle dermal rather than dermoglandular. The pedicle is thicker at the base like a pyramid. The dissection is then done behind the breast, separating it from the prepectoral fascia in an avascular plan. The entire volume of breast tissue to be resected is then removed as one block. The fist of the hand can be now introduced centrally into the breast core to reach behind the nipple- areola and up to its upper limit to create a roomy space for the pedicle (Fig. 1b).

In-setting of the new nipple-areola complex (NAC) was done first, with burse string periareolar suture was taken. This was followed by suturing the medial and lateral pillar and closure of skin. A suction drain is introduced in each breast. The drain will stay in for up to $24-48 \mathrm{hr}$, and a piece of nonadhesive Vaseline gauze is placed on each areola. Light dressings are applied, and the patient is put in a bra, which she will wear day and night for up to 6 weeks.

\section{RESULTS}

The surgical procedure was easily performed with no danger on the vascularity of the nippleareola complex or of the skin flaps. The excised parenchyma ranged from $850 \mathrm{ml}-1500 \mathrm{ml}$. Only few minutes were needed to de-epithelize the pedicle. Undermining of the upper breast from the deep (pectoral) fascia was easily performed in an avascular plane with no blood loss and no affection of the vascularity of the nipple-areola complex. Thinning of the pedicle was done easily with cutting electrocautery without any danger on the vascularity of the nipple-areola complex. No blood transfusion was needed in any of our patients.

Excellent results with good upper pole fullness were obtained immediately on the operating table. Most of the patients were satisfied with the fine periareolar scar, the size of the breasts, and the sensation of the nipple-areolar complex. No disruption at the periareolar suture line occurred. None of our patients showed persistent periareolar wrinkles postoperative.

Partial affection of areola vascularity occurred in one patient with previous application of port-acath on the same side chest wall. Unilateral affection of sensation occurred in two patients. Three of our patients showed widening of the periareolar scars postoperative and needed secondary correction. The periareolar scar widening occurred due to weakening or exposure of the periareolar purse string suture leading to its early removal. Otherwise, the results were good and satisfactory as regard the shape, volume, vascularity of nipple-areolar complex, and nipple-areolar complex sensation. Follow-up of patients after six months postoperative showed persistent good results with un-noticeable scars, maintenance of upper pole fullness, with no bottoming out occurred in any of our patients. Figs. $(2,3,4)$ show on the right side the post-operative photos of the breasts of three of our patients. 

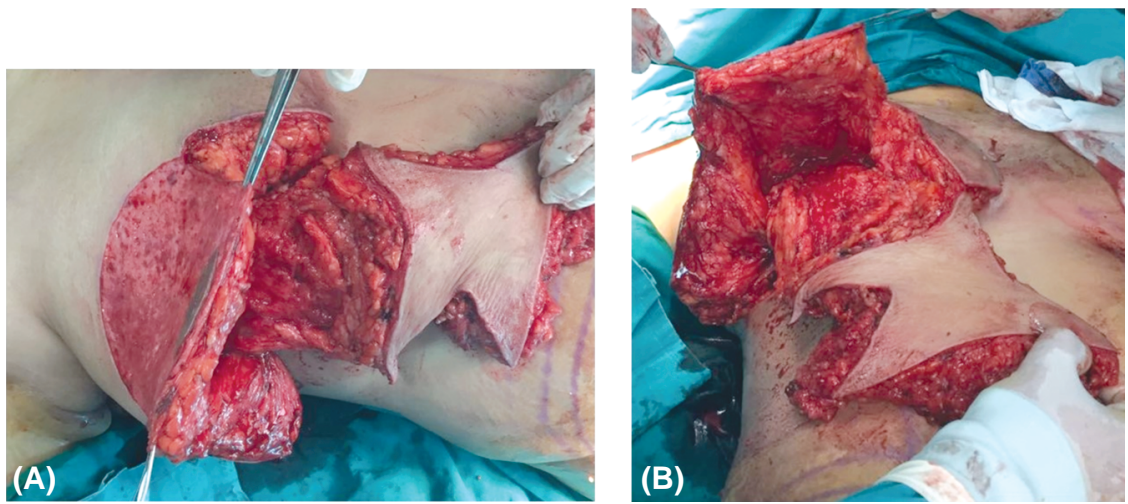

Fig. (1): (A): Intraoperative photo shows thinning of the superior pedicle after extending the parenchymal resection upward underneath the nipple-areola complex, with the superior pedicle is thinned out distally up to 2 $3 \mathrm{~cm}$ in thickness. (B): Intraoperative photo shows creation of a roomy space centrally into the breast core reaching to the upper limit of the breast to facilitate transposition and insetting of the long superior pedicle.
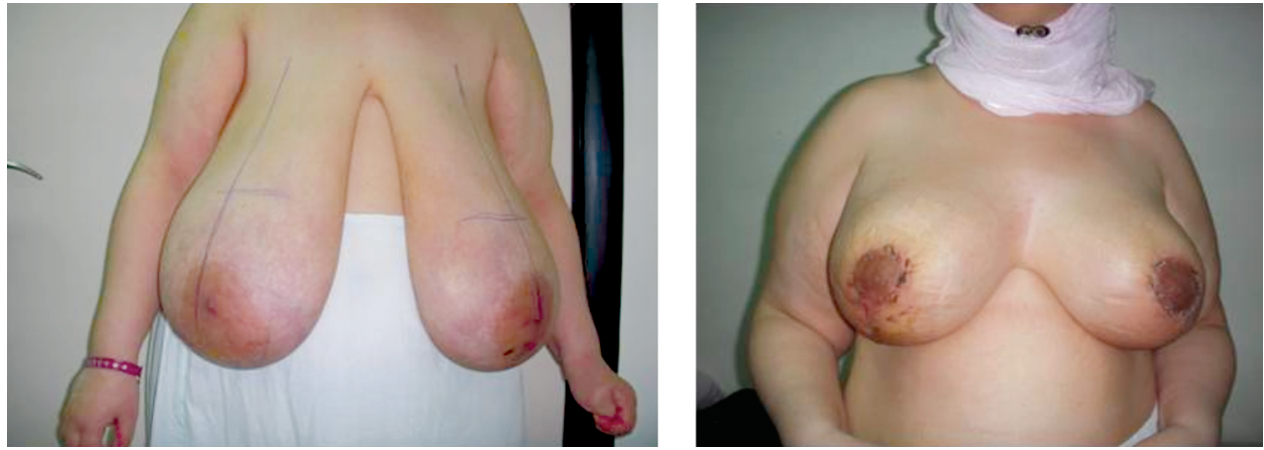

Fig. (2A): Frontal view of the breast of a 40 years old female patient with the preoperative photo on the left side and the postoperative photo on the right side.
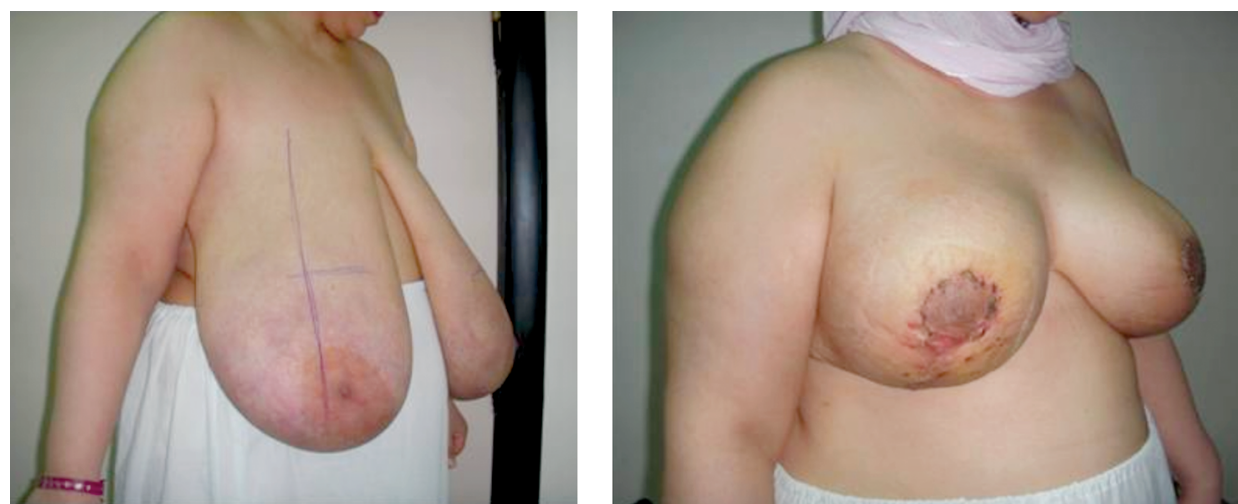

Fig. (2B): Right oblique view of the breast of the same patient with the preoperative photo on the left side and the postoperative photo on the right side.
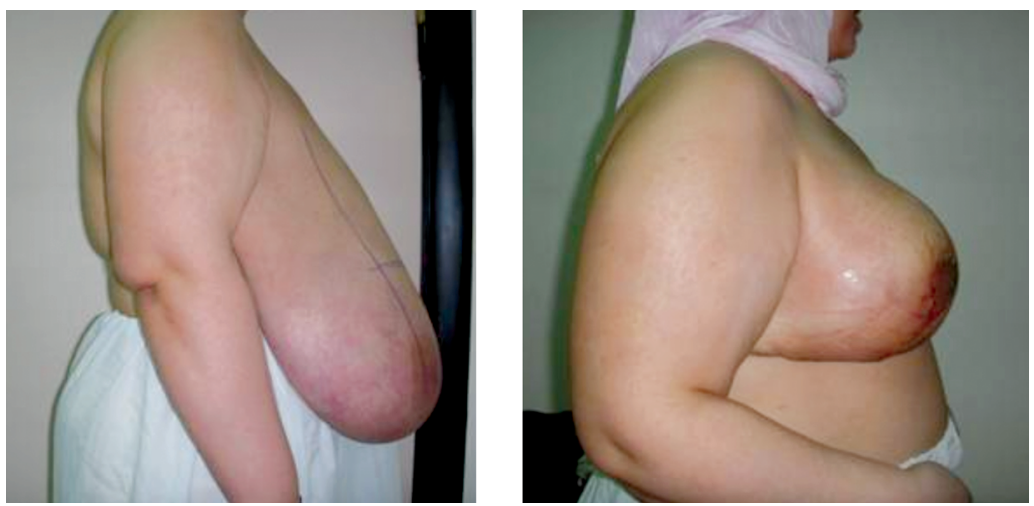

Fig. (2C): Right dead lateral view of the breast of the same patient with the preoperative photo on the left side and the postoperative photo on the right side. 


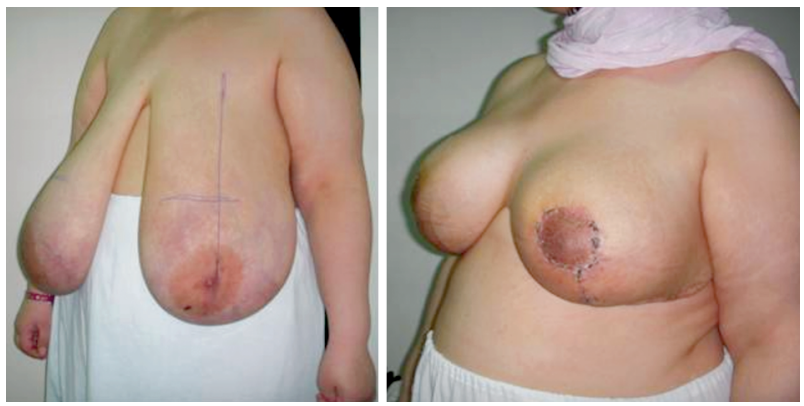

Fig. (2D): Left oblique view of the breast of the same patient with the preoperative photo on the left side and the postoperative photo on the right side.
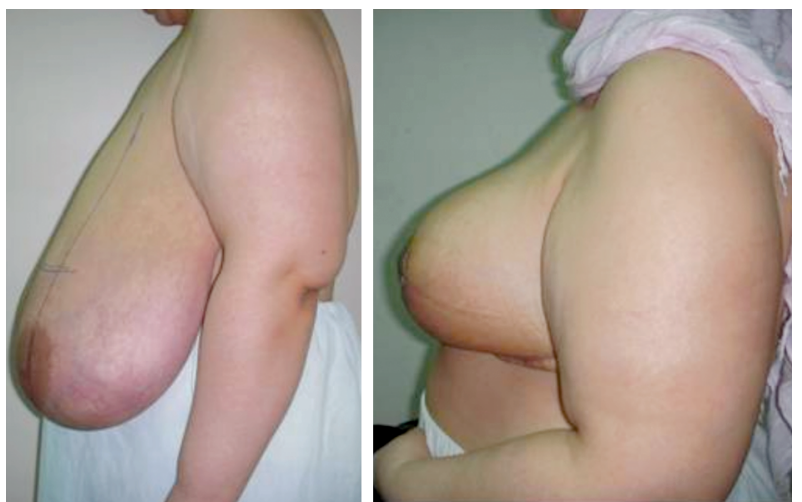

Fig. (2E): Left dead lateral view of the breast of the same patient with the preoperative photo on the left side and the postoperative photo on the right side.

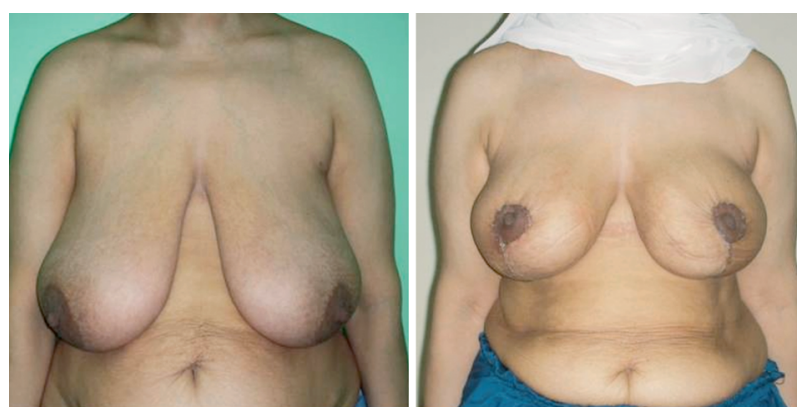

Fig. (3A): Frontal view of the breast of a 43 years old female patient with the preoperative photo on the left side and the postoperative photo on the right side.
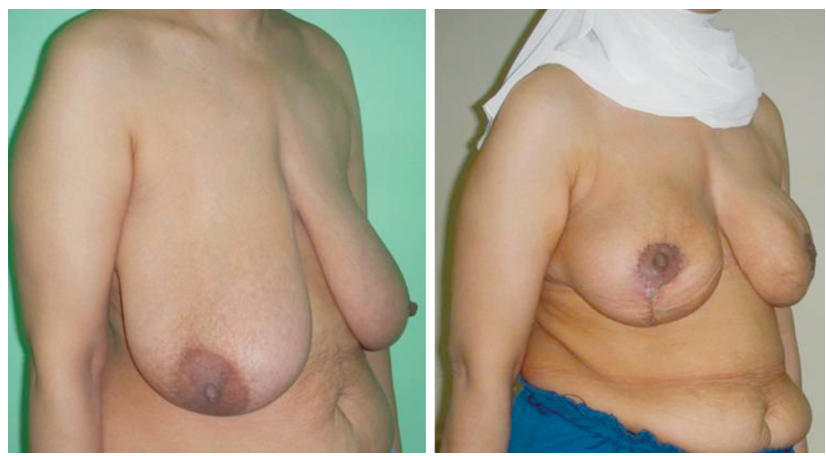

Fig. (3B): Right oblique view of the breast of the same patient with the preoperative photo on the left side and the postoperative photo on the right side.
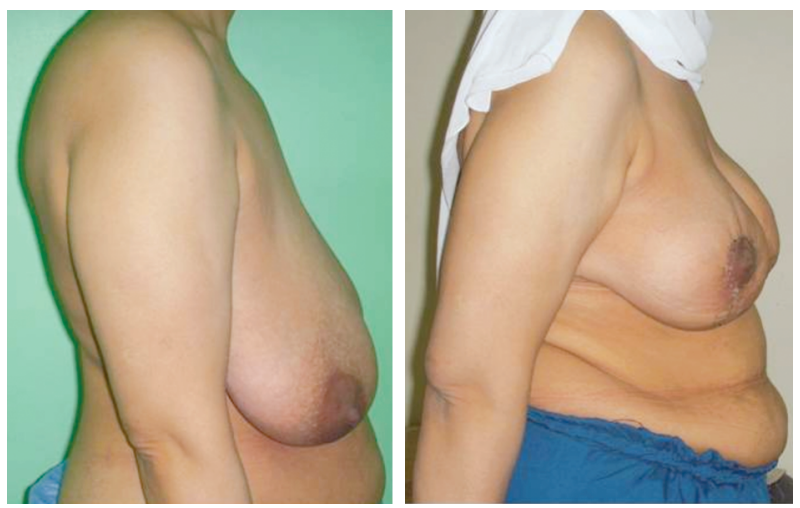

Fig. (3C): Right dead lateral view of the breast of the same patient with the preoperative photo on the left side and the postoperative photo on the right side.

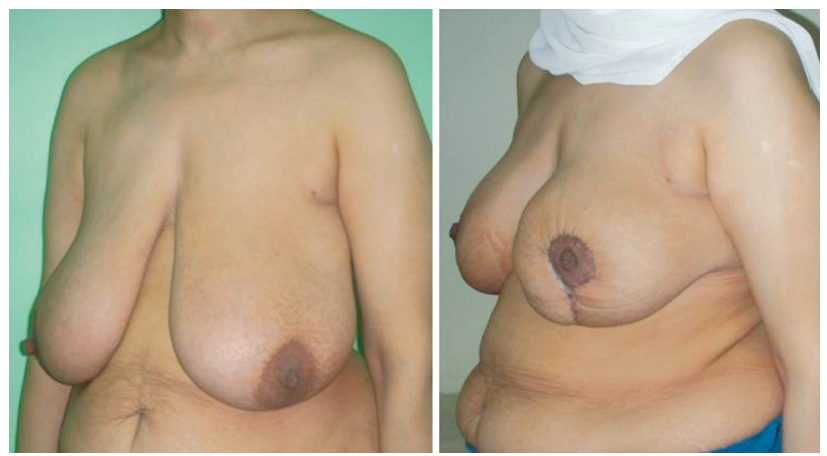

Fig. (3D): Left oblique view of the breast of the same patient with the preoperative photo on the left side and the postoperative photo on the right side.
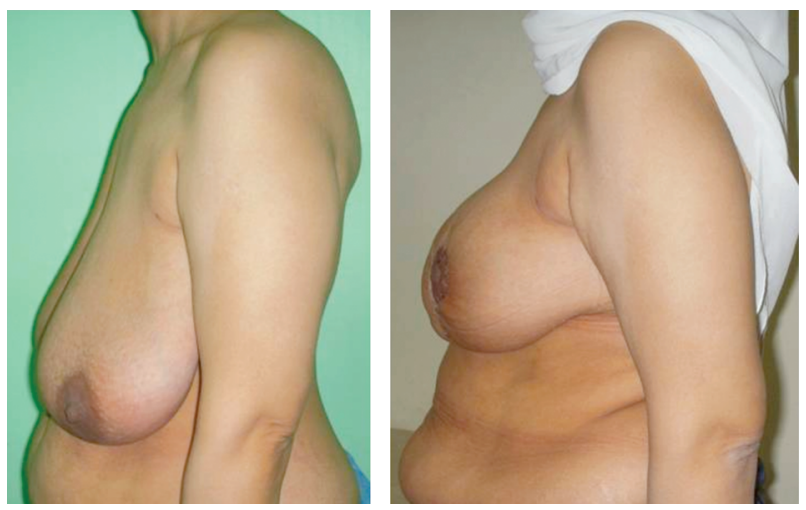

Fig. (3E): Left dead lateral view of the breast of the same patient with the preoperative photo on the left side and the postoperative photo on the right side.

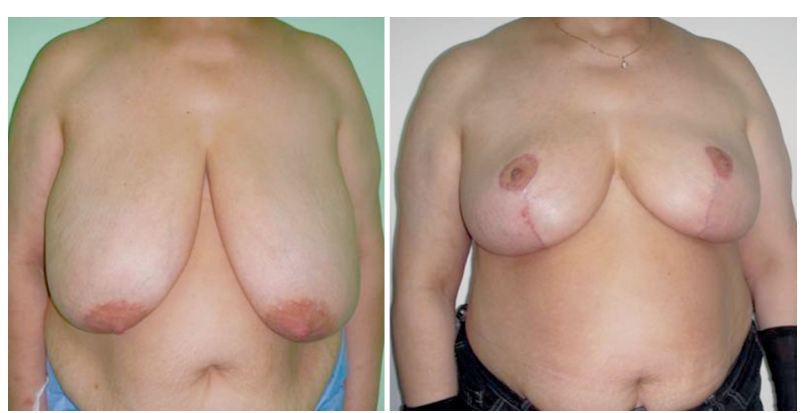

Fig. (4A): Frontal view of the breast of a 46 years old female patient with the preoperative photo on the left side and the postoperative photo on the right side. 

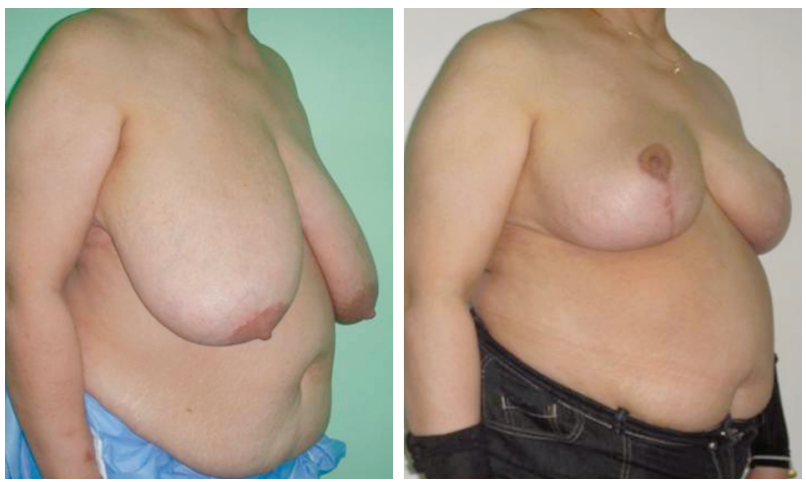

Fig. (4B): Right oblique view of the breast of the same patient with the preoperative photo on the left side and the postoperative photo on the right side.
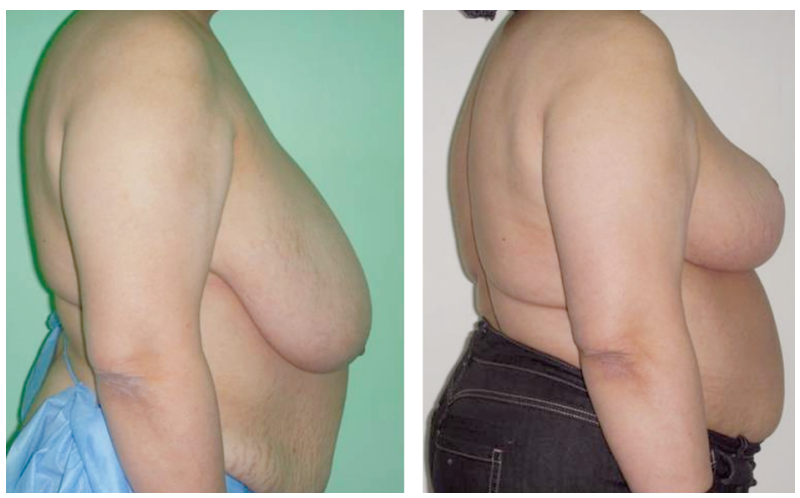

Fig. (4C): Right dead lateral view of the breast of the same patient with the preoperative photo on the left side and the postoperative photo on the right side.
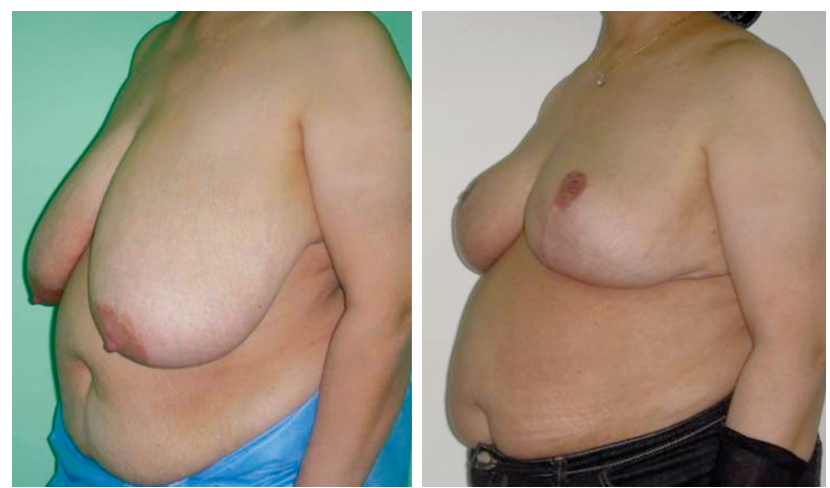

Fig. (4D): Left oblique view of the breast of the same patient with the preoperative photo on the left side and the postoperative photo on the right side.
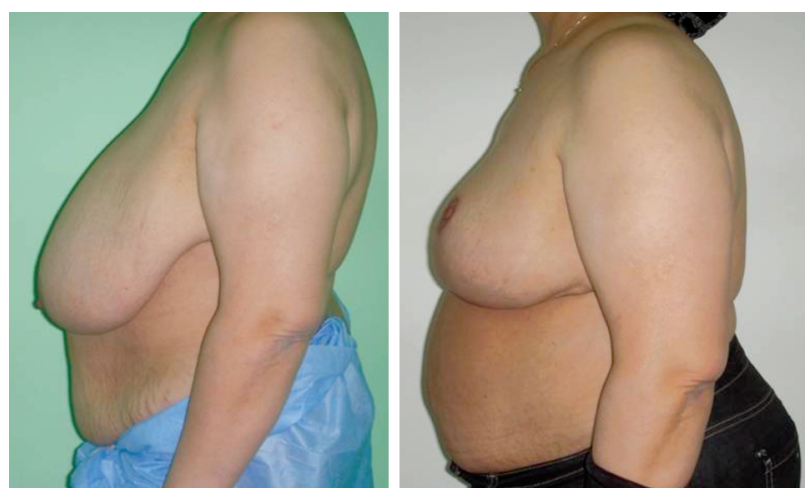

Fig. (4E): Left dead lateral view of the breast of the same patient with the preoperative photo on the left side and the postoperative photo on the right side.

\section{DISCUSSION}

Very large breasts "gigantomastia" associated with severe ptosis frequently present a challenge to the plastic surgeon in choosing the ideal procedure to obtain a satisfactory result [19]. A free nipple graft, which for many presents the best option in these conditions, has many disadvantages [20].

Different pedicles can be used for transfer of nipple-areola complex to its new position. However, the superior pedicle described by Weiner et al., in 1973, has traditionally been associated with smaller resections [21], best used in resections of less than $1000 \mathrm{~g}$, as it becomes difficult to inset with larger resections, due to the risk of kinking of the pedicle and the associated risk of affecting the pedicle vascularity [22]. Although previously reported that superior pedicle was not ideal for larger resections, there was a reported role for the superior pedicle in severely ptotic breasts as it leaves upper-pole fullness and maintains breast projection. It has been demonstrated to be a safe option in ptotic breasts in women with sternal notch to nipple distances $>40 \mathrm{~cm} \mathrm{[23].}$

We can conclude that superior pedicle is a safe technique even with undermining and thinning of this pedicle, because previous anatomical studies proved that the vascularity is reaching this pedicle superficially, through superficially located branches that circumscribes the areola and through the strong connection and anastomoses between the subdermal and preglandular plexuses [24,25].

The progressive improvement in reduction mammoplasty contributed to Lejour [12,13], Lassus [9-11], Hall-Findlay [26], Ramirez [15] and others who gave results with dramatic improvement in the size and length of the resulting scar, but left the upper pole still deficient [27]. And still the huge breast size or what is called "gigantomastia" remain a problematic case in choosing the technique and the pedicle to be used in its reduction.

In our modification, the upper pole fullness was obtained through transposing and in-setting the superior pedicle after its undermining and thinning and dissecting it from the pre-pectoral fascia. As regard the incision, we adopted the Owl incision described by Ramirez [15]. It combines the features of the large periareolar reduction of Benelli [14] and the vertical reduction of Lassus [9-11] and Lejour [12,13]. The seating Owl incision combines different incisions to maximize the advantages and positive aspects of each incision and to diminish their negative features [15]. Enlargement 
of the periareolar skin resection diminished the length and pleating of the vertical scar. Conversely, inclusion of the vertical component to the periareolar technique eliminated the pleating effect of the periareolar incision [15].

Ramirez [15], described the technique of reduction mammoplasty using the Owl incision with no undermining. And he concluded from his study that the owl-type incision and the superio-central pedicle flap are elements of a reduction mammoplasty technique that provides excellent projection and shape with minimal visible scars. Additionally, it may better preserve the sensation to the nippleareolar complex, and lactation is not compromised.

Despite that the Owl technique of Ramirez gives good results in moderate size breast hypertrophy and in cases of severe ptosis of the breast [15], but in huge breasts there is a difficulty in resecting a large volume of breast parenchyma due to "no undermining" technique of the pedicle, in addition to the difficulty in transposing and insetting such long bulky superio-central pedicle, which will make closure at the nipple-areola junction under severe tension, making it liable for widening and making it exposed to transient stage of venous congestion at the nipple-areolar level.

In our current technique, in-setting the areola and starting the closure with periareolar closure first to distribute the tension before suturing the pillars allowed the adjustment of the tension and prevented wound disruption at the periareolar suture line. This modification was done after experiencing disruption at the periareolar suture line in two of the early cases done previously by the senior author in another previous study [16]. Suturing of the medial and lateral pillars was adjusted after that, so that it did not add any more tension.

However, in previous work by the senior author to decrease the tension applied at the periareolar suture line, pillars were sutured with loose sutures giving the shape of clefted breast at the midline (at the site of the vertical scar) [16]. In our current modification, with undermining and thinning of the superior dermal pedicle, we resect a larger amount of breast parenchyma from underneath the nipple-areola complex and from the upper pole of the breast. This thinning have many advantages, as it allows larger volume resection of breast tissues, so, our modification enable us to apply this technique even in patients with very huge breast hypertrophy "gigantomastia", another advantage is that superior pedicle thinning allows a wider roomy space at the upper pole of the breast to transpose and inset the areola easily and comfortably with no tension at the periareolar closure, avoiding the problem of areolar widening and congestion.

Lejour [12,13] \& Findley [26] were performing the superior pedicle technique only dermal, and then Gheita did thinning for the superior pedicle up to $2 \mathrm{~cm}$ in thickness, that was reported for management of massive breasts with marked ptosis or "gigantomastia" [19]. As in 2009 Gheita invented the "super flap" or the superior pedicle extra-long flap mammoplasty technique. It allows for very long flaps, in some cases over $40 \mathrm{~cm}$, and breast ptosis with the nipple at more than $55 \mathrm{~cm}$ from the suprasternal notch, with preservation of the circulation to the nipple-areola complex [19]. This procedure has been developed and modified from the French oblique method of Dufourmentel and Mouly [28] converted to an inverted $T$, while the glandular resection is performed in a keel fashion behind the areola to house and give room for these very long flaps without undue compression on them and endangering the blood supply to the nipple-areola complex. And concluded that this method is suitable for very large breasts with ptosis. Most of the time he obtain appealing and attractive breasts, and rarely resulted in complications [19].

Gheita created a roomy space inside the breast behind the empty superior pole and the new areola site to lodge comfortably the superior pedicle flap and avoid congestion. This also will allow proper filling of the breast and give it a pleasing, smooth conical shape. But he left the uppermost part of the breast above the site of the new areola attached to the chest wall. As he reported that this will leave all the vessels coming from above and the perforators intact in their way to vascularize the pedicle [19]. In our technique, we are creating a roomy space at the upper pole of the breast which extend up to the uppermost part of the breast above the level of the new areola to allow easier transposition of the pedicle, with no compromise of the blood supply to nipple-areola complex reported.

The width of the pedicle in Gheita study reported to be about $10 \mathrm{~cm}$ (about $90^{\circ}$ of a circle), and its thickness is $2 \mathrm{~cm}$, especially in very long flaps, as in marked ptosis [19]. While in our technique the width of the pedicle was approximately $270^{\circ}$ of a circle, with deskinning only to the adjacent part just medial and lateral to the pedicle, to preserve the subcutaneous plexus and to allow more cutaneous perforator branches to reach and supply the nipple-areola complex, and also to allow more sensory nerves to reach and supply the nipple- 
areola complex. But with this greater width of pedicle $\left(270^{\circ}\right.$ of a circle), it makes the insetting of the pedicle more difficult if no roomy space available to inset it. This roomy space allow to lodge comfortably the pedicle and avoid congestion of nipple-areola complex. This also will allow proper filling of the breast and give it a pleasing, smooth conical shape.

Previously reported that a major disadvantage of the superior pedicle technique is the higher risk for sensory loss at the nipple-areolar complex postoperatively [29]. This is found to be independent of the amount of tissue resected and is thought to be due to the tissue resection at the base of the breast this pedicle requires. Numbers as high as $70 \%$ of women have diminished sensation at the nipple-areolar complex 1 year postoperative with the superior pedicle, irrespective of the amount of tissue resected [30]. In our study, we didn't experience such complication except only in two cases (4\%) who complained from unilateral affection of sensation, which is not a significant number.

\section{Conclusion:}

Our modification in the form of thinning of the superior pedicle, making it dermal rather than dermoglandular, enable us to use Ramirez technique in reduction of the huge breasts of different sizes, with reliable successful results. Advantages of our modification are the excellent flap vascularity (thin superior dermal pedicle), with no traction or rotation of the pedicle. This technique can be applied safely to all shapes and sizes of the breast. Maintenance of fullness at the upper pole of the breast and behind the nipple-areola complex with good shape and projection of the breast is a major advantage for this technique. The surgical procedure was easily performed with no danger on the vascularity of the nipple-areola complex or the skin flaps, in addition to the short surgical time and the steep learning curve. The technique is reproducible and straightforward, and resulting in excellent longterm results with no bottoming out, and can be applied safely in gigantomastia cases.

\section{REFERENCES}

1- Romrell L.J. and Bland K.I.: Anatomy of the Breast, Axilla, Chest Wall, and Related Metastatic Sites. In Bland K.I. and Copeland E.M. (eds.): The Breast; Comprehensive Management of Benign and Malignant Diseases. Philadelphia; Saunders Company, 1991.

2- Moore K. and Persaud T.: The Developing Human- Clinically Oriented Embryology. $6^{\text {th }}$ Ed. Philadelphia: Saunders Company, 1998.

3- Hunt K.K., Newman L.A., Copeland E.M. and Bland K.I.: Chapter 17. The Breast. In: Brunicardi F.C., Andersen
D.K., Billiar T.R., Dunn D.L., Hunter J.G., Matthews J.B., Pollock R.E., editors. Schwartz's Principles of Surgery. $9^{\text {th }}$ Ed. New York: McGraw-Hill, 2010.

4- Sabel M.S.: Surgical Foundations: Essentials of Breast Surgery. $1^{\text {st }}$ Ed. Philadelphia: Mosby Inc., 2009.

5- Palmar J.H. and Taylor G.I.: The Vascular Territories of the Anterior Chest Wall. Br. J. Plast. Surg., 39: 287, 1986.

6- Corduff N. and Taylor G.I.: Subglandular Breast Reduction: The Evolution of a Minimal Scar Approach to Breast Reduction. Plast. Reconstr. Surg. J., 113: 175, 2004.

7- Ricbourg B.: Applied Anatomy of the Breast: Blood Supply and Innervation. Ann. Chir. Plast. Esthet., 37 (6): 603, 1992. Quoted from White D.J. and Maxwell G.P. Breast Reduction. In Guyuron B. (ed.): Plastic Surgery; Indication, Operation and Outcomes. St. Louis; Mosby, Inc., p. 2705, 2000.

8- Choa B.C., Yanga J.D., Baikb B.S., et al.: Periareolar Reduction Mammoplasty Using an Inferior Dermal Pedicle or a Central Pedicle. J. of Plast, Reconstruct \& Aesth. Surg., 61 (3): 275, 2008.

9- Lassus C.: A Technique for Breast Reduction. Int. Surg., 53: 69, 1970.

10- Lassus C.: Breast Reduction: Evolution of a Technique. A Single Scar. Aesth. Plast. Surg., 11: 107, 1987.

11- Lassus C.: Update on Vertical Mammaplasty. Plast. Reconstr. Surg., 104: 2289, 1999.

12- Lejour M.: Vertical Mammaplasty and Liposuction of the Breast. Plast. Reconstr. Surg., 94: 100, 1994.

13- Lejour M.: Vertical Mammaplasty: Early Complications after 250 Personal Consecutive Cases. Plast. Reconstr. Surg., 104: 764, 1999.

14- Benelli L.: A New Periareolar Mammaplasty: The "Round block" Technique. Aesthetic Plast. Surg., 14: 93, 1990.

15- Ramirez O.M.: Reduction Mammoplasty with the "Owl" Incision and No Undermining. Plast. Reconstr. Surg., 109 (2): 512; discussion 523, 2002.

16- Safe I., Elshahat A. and Hussein H.: Restoring Upper Pole Fullness in Reduction Mammaplasty and Mastopexy. Egypt, J. Plast. Reconstr. Surg., 31 (1): 57, 2007.

17- Nahai F.: Vertical Reduction. Operative Techniques. Plast. Reconstr. Surg., 6: 97, 1999.

18- Nahai F.: Superior Pedicle Vertical Scar Mammaplasty: Surgical Technique. In: Hamdi M., Hammond D.C., Nahai F. (eds) Vertical Scar mammoplasty. Springer, Berlin, Heidelberg, Chapter 4: 25, 2005.

19- Gheita A.: Mammoplasty: The "Super Flap" or the Superior Pedicle Extra Long Flap for Massive Breasts with Marked Ptosis or Gigantomastia. Aesthetic Plast. Surg., 33 (3): $461,2009$.

20- Colen S.R.: Breast Reduction with the Use of Free Nipple Graft Technique. Aesthetic Surg. J., 21 (3): 261, 2001.

21- Weiner D.L., Aiache A.E., Silver L., et al.: A Single Dermal Pedicle for Nipple Transposition in Subcutaneous Mastectomy, Reduction Mammaplasty, or Mastopexy. Plast. Reconstr. Surg., 51: 115, 1973.

22- Hall-Findlay E.J.: Pedicles in Vertical Breast Reduction and Mastopexy. Clin. Plast. Surg., 29: 379, 2002. 
23- Wettstein R., Christofides E., Pittet B., et al.: Superior Pedicle Breast Reduction for Hypertrophy with Massive Ptosis. J. Plast. Reconstr. Aesthet. Surg., 64: 500, 2011.

24- Lalardrie J.P. and Jouglard J.P.: Morphologie et anatomie du sein "normal". In: Chirurgie Plastique du Sein. Masson et Cie, Paris, pp 19-26, 1974. Quoted from Gheita A \& Moftah A. Breast Ptosis Managed by Mastopexy Using the Triple Flaps Procedure. Aesth. Plast. Surg., 35: 107, 2011.

25- Bricout N.: Hypertrophy and Ptosis. In: Breast Surgery. Springer-Verlag, Paris, pp 71-162, 1996.

26- Hall-Findlay E.J.: A Simplified Vertical Reduction Mammoplasty Shortening the Learning Curve. Plast. Reconstr. Surg., 104: 748, 1999.
27- Graf R. and Biggs T.M.: In Search of Better Shape in Mastopexy and Reduction Mammoplasty. Plast. Reconstr. Surg., 110: 309, 2002.

28- Dufourmentel C. and Mouly R.: Mammoplasty by the Oblique Method. Ann. Chir. Plast., 6: 45, 1961.

29- Chiummariello S., Angelisanti M., Arleo S., et al.: Evaluation of the Sensitivity After Reduction Mammoplasty. Our Experience and Review of the Literature. Ann. Ital Chir., 84: 385, 2013

30- Schlenz I., Rigel S., Schemper M., et al.: Alteration of Nipple and Areola Sensitivity by Reduction Mammaplasty: A Prospective Comparison of Five Techniques. Plast. Reconstr. Surg., 115: 743; discussion 752, 2005. 